\title{
Diffusion Characteristics of Solar Beams Radiation Transmitting through Greenhouse Covers in Arid Climates
}

\author{
Ibrahim Al-Helal ${ }^{1, *}$, Abdullah Alsadon ${ }^{2} \odot$, Mohamed Shady ${ }^{1}$, Abdullah Ibrahim ${ }^{2}$ and \\ Ahmed Abdel-Ghany ${ }^{1, * \mathbb{D}}$ \\ 1 Department of Agricultural Engineering, College of Food and Agriculture Sciences, King Saud University, \\ P.O. Box 2460, Riyadh 11451, Saudi Arabia; mshady@ksu.edu.sa \\ 2 Department of Plant Production, College of Food and Agriculture Sciences, King Saud University, \\ P.O. Box 2460, Riyadh 11451, Saudi Arabia; alsadon@ksu.edu.sa (A.A.); adrahim@ksu.edu.sa (A.I.) \\ * Correspondence: imhelal@ksu.edu.sa (I.A.-H.); aghany@ksu.edu.sa (A.A.-G.)
}

Received: 2 December 2019; Accepted: 16 January 2020; Published: 18 January 2020

\begin{abstract}
In hot and sunny regions, extensive solar radiation transmitted into greenhouses makes it essential to select a greenhouse cover with specific characteristics. Reflection and diffusion are the most important properties of covers for reducing solar heating load and scattering solar beams for better growth of plants. Three types of plastic films that are commonly used for covering greenhouses in arid climate were selected for this study. These were reflective-diffusive $(R D F)$, diffusive $(D F)$, and locally produced $(C F)$ films. The films were used to cover three identical twin-span greenhouse models; the radiation components, air temperature $\left(T_{\mathrm{i}}\right)$, and relative humidity $\left(R H_{\mathrm{i}}\right)$ were measured in each model. Transmission of solar radiation through each cover was characterized by determining: (i) The beam that is diffused during transmission, and (ii) the unscattered beam that is transmitted directly through the film. The results show that the diffuse radiation transmitted through the $D F$, $R D F$, and $C F$ covers was enhanced, respectively by $77 \%, 85 \%$, and $109 \%$ as a result of diffusing $34 \%$, $33 \%$, and $43 \%$ of the transmitted beam radiation by the $D F, R D F$, and $C F$ covers, respectively during transmission. The diffusive nature of the tested covers increased the ratio of diffuse to direct beam radiation $(D / B)$ from 0.3 outside the greenhouse to $0.77,0.69$, and 0.95 inside a greenhouse covered with $D F, R D F$, and $C F$, respectively. At around noon, the $C F$ cover decreased $T_{\mathrm{i}}$ by about $5-10{ }^{\circ} \mathrm{C}$ and increased $R H_{\mathrm{i}}$ by about $3 \%-5 \%$ compared to those under the $D F$ and $R D F$ covers. However, $D F$ and $R D F$ covers showed almost similar effects in $T_{\mathrm{i}}$ and $R H_{\mathrm{i}}$. The low-price $C F$ cover showed higher diffusive-radiative properties than $D F$ and $R D F$ covers and can serve effectively in arid climate as an alternative covering material.
\end{abstract}

Keywords: greenhouse; plastic film; solar beam radiation; transmission; diffusion; reflection

\section{Introduction}

During the last decade, greenhouses have been extensively used for crop production in hot and sunny (arid) regions to provide a suitable environment for plant growth [1]. This is because in arid regions, as in the Arabian Peninsula, high solar irradiance (up to $1200 \mathrm{~W} \mathrm{~m}^{2}$ around noon), high air temperature (above $45^{\circ} \mathrm{C}$ ), and low relative humidity (below $15 \%$ ) are the common weather during most of the months [2,3]. This, in addition to the high salinity and scarcity of water resources in arid regions, make growing crops in open fields very difficult [3,4]. Due to the extremely high ambient air temperature in summer, the inside greenhouse air temperature exceeds $50{ }^{\circ} \mathrm{C}$ and therefore, cooling the greenhouse air becomes extremely important for controlling the microclimate to appropriate levels for crop growth $[1,3,5]$. In addition to the well-known evaporative cooling and shading methods, 
the heat prevention method is also used for cooling the greenhouse air in hot and sunny regions (arid climate) [5]. Through heat prevention methods, the radiation heat load can be reduced before it enters the greenhouse by excluding a portion of the incident solar radiation on the greenhouse cover $[5,6]$. This is accomplished by using selectively reflecting films (i.e., reflecting the near infra-red radiation, NIR, and transmitting photosynthetically active radiation, PAR) or totally reflecting films to reflect a portion of solar radiation over the whole solar radiation spectrum band (200-2500 nm) [7]. The NIR-reflecting film covering a greenhouse reduces the inside greenhouse air temperature by $1-2{ }^{\circ} \mathrm{C}$ at around noon and by $4-5^{\circ} \mathrm{C}$ in the morning and afternoon [8]; however, the lifetime of these covers is very short (few months) due to the NIR reflective additives added to the polymers [5,7,8]. In addition, the temperature reduction is not enough in regions where the ambient temperature exceeds $45^{\circ} \mathrm{C}$ in summer. One of the main characteristics of greenhouse covers is the diffusive power of the film that enables it to forward scatter (diffuse) solar beam radiation during transmission. This allows plants in the greenhouse to receive solar light (photosynthetically active radiation, PAR: 400-700 nm) homogeneously from all sides $[9,10]$. Therefore, the extent to which the transmitted beams radiation into the greenhouse is diffused can be of considerable importance for increasing the interception of solar visible light (PAR) by plants and consequently, stimulating photosynthesis [11,12]. Recently, several companies worldwide have begun producing several types of long-life reflecting and diffusing films for covering greenhouses in hot climates $[9,10]$. Growers select covers based on crop, outside climate in which the greenhouse is located, and market situation [9]. These types of films are commercially available in local markets; however, their suitability for covering greenhouses in hot and sunny regions and their transmission characteristics need to be addressed properly to explore the performance of these films under arid climatic conditions. The reflection and diffusion characteristics of solar beam radiation depend on solar elevation and its intensity, and the radiochemical properties of the film itself, such as the type of additives and microstructure of the film material. Research groups have investigated the effects of diffuse solar radiation and its spatial distribution in the greenhouse on the crop yield, morphology, and productivity [9-12]. However, their studies used greenhouses under climatic conditions different from the arid climate. Based on our knowledge, studies describing the characteristics of solar radiation transmitted through plastic film covering materials under arid climatic conditions are not available.

In the previous studies, the fraction of diffuse radiation that is transmitted into a greenhouse is usually derived from the diffuse incident radiation and the cover transmittance to diffuse radiation [13-20]. Due to lack of information, these studies have neglected the diffusion effect of the covering materials on the solar beam radiation. Yet, most cover films diffuse a considerable amount of beam radiation during transmission. This means that the fraction of diffuse radiation under a plastic film cover is higher than that over the cover. Few studies assumed that a portion of the beam radiation transmitted through a plastic film cover scatters forward diffusively (diffused beams) and that the remaining portion is transmitted directly (unscattered beams) [21-23]. The transmission mechanism and the different components of solar radiation transmitted through a plastic film covering greenhouse are illustrated in Figure 1. The incident atmospheric diffuse radiation $\left(D_{\mathrm{i}}\right)$ is transmitted through the cover diffusively $\left(D_{\mathrm{t}}\right)$. A portion, $\sigma$, of the transmitted beam radiation $\left(B_{\mathrm{t}}\right)$ scatters forward during transmission (i.e., diffused beam, $\sigma B_{\mathrm{t}}$ ) and adds to the transmitted diffuse radiation. The remaining portion, $(1-\sigma) B_{\mathrm{t}}$, is transmitted directly as beams (unscattered beams, $B_{\mathrm{u}}$ ). In general, for greenhouse covering, the reflective film is usually used for reducing the solar heating load, as well as the inside greenhouse air temperature and the diffusive film is used for enhancing the diffuse radiation in the greenhouse. 


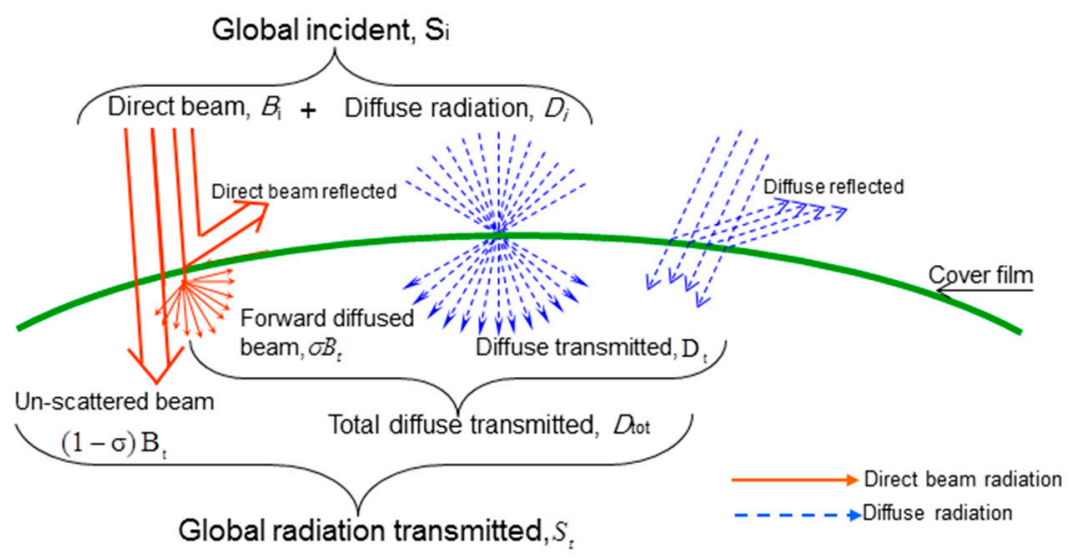

Figure 1. Schematic diagram showing the transmission mechanism and the components of solar radiation transmitted through a plastic film.

The aim of this study was to answer three questions: (i) Is the diffusive film able to reduce the inside greenhouse temperature due to diffusion? (ii) is the reflective film able to diffuse the beam radiation too? and (iii) what are the transmission characteristics of these films in dry and intensive solar radiation conditions (arid climate)? Therefore, three types of films that are commonly used for covering the greenhouses in the Arabian Peninsula were selected for this study. The films were: A locally produced film as control treatment $(C F)$, a diffusive film $(D F)$, and a reflective-diffusive film $(R D F)$. The three films were used to cover three identical small-scale, twin-span, crop-free experimental greenhouse models. The three covers were evaluated in order to (i) characterize the different components of solar radiation transmitted through each film, (ii) determine the capability of each film to diffuse beam radiation, and (iii) determine the capability of each film to improve the inside of greenhouse environment.

\section{Materials and Methods}

\subsection{Theoretical Analysis}

A common method for determining the radiative properties of a plastic film related to diffuse solar irradiance is to fix two pyranometers above and below the film and prevent the direct beam component from reaching the pyranometers and the film under test. In this case, the two pyranometers detect the diffuse radiation below and above the film. To determine the direct beam and diffuse radiation components simultaneously, two pyranometers are used. One is used to measure the global radiation $\left(S_{\mathrm{i}}\right)$ and the other is shaded using an opaque disk (shaded pyranometer hereafter) to detect the diffuse component $\left(D_{\mathrm{i}}\right)$ at the same time [22]. The disk will prevent a part of the diffuse solar radiation from reaching the pyranometer dome; therefore, a correction factor $\left(F_{\mathrm{c}}>1\right)$ is used. Thus, for the measured global $\left(S_{\mathrm{i}}\right)$ and diffuse $\left(D_{\mathrm{i}}\right)$ radiations incident on a cover surface, the direct beam component $\left(B_{\mathrm{i}}\right)$ is

$$
B_{i}=S_{i}-D_{i}
$$

As shown in Figure 1, during the transmission of solar beam radiation through a plastic film, a portion of the incident beam is diffused forward as it passes through the film. This means that a fraction $\sigma$ of the transmitted beam $\left(B_{\mathrm{t}}\right)$ is diffused. The fraction $\sigma$ (called the diffusion coefficient) is defined as the ratio of the beam radiation scattered diffusively during transmission to the total beam transmitted [22]. Thus, the measured diffuse transmitted radiation $\left(D_{\text {tot }}\right)$ will include this portion (Figure 1). Therefore,

$$
D_{t o t}=D_{t}+\sigma B_{t}
$$


The remaining portion of the transmitted beam radiation will pass directly through the film (unscattered beams, $B_{\mathfrak{u}}$ ). The amount of this portion is equal to $(1-\sigma) B_{\mathrm{t}}$ and according to Figure 1 , this portion is given by

$$
(1-\sigma) B_{t}=S_{t}-D_{t o t}
$$

The value of the total beam transmitted $\left(B_{\mathrm{t}}\right)$ cannot be measured directly because a portion $\sigma$ of this beam is diffused during transmission, whereas the incident components $\left(S_{\mathrm{i}}\right.$ and $\left.D_{\mathrm{i}}\right)$, as well as the transmitted components $\left(S_{\mathrm{t}}\right.$ and $\left.D_{\text {tot }}\right)$ can be measured by using the two pyranometers method. The ratio of the measured parameters $\left(D_{\text {tot }} / D_{\mathrm{i}}\right)$ gives an apparent transmittance $\left(\bar{\tau}_{D}\right)$ of a plastic film to diffuse solar radiation ( $\bar{\tau}_{D}$ is higher than one for diffusive plastic films). However, the true transmittance of a plastic film to diffuse radiation $\left(\tau_{D}=D_{t} / D_{i}\right)$ is usually estimated by exposing the film and the measuring devices totally to diffuse radiation and measuring values of $D_{\mathrm{i}}$ and $D_{\mathrm{t}}$ under such conditions. Combining and modifying Equations (2) and (3) gives the diffusion coefficient $(\sigma)$ as a function of measured parameters as

$$
\sigma=\left(D_{t o t}-\tau_{D} D_{i}\right) /\left(S_{t}-\tau_{D} D_{i}\right)
$$

The diffusive films are designed to diffuse a considerable amount of beam radiation during transmission. Thus, the diffusive film cover should enhance the transmitted diffuse radiation and the enhancement percentage $(E)$ can be estimated as [22] by

$$
E=\left(\bar{\tau}_{D} / \tau_{D}-1\right) \times 100
$$

\subsection{The Three Films Tested}

Three types of plastic films that growers commonly use for covering greenhouses in hot and sunny regions were selected for this study. Two films were supplied by Plastika Kritis SA (Iraklion Crete, Greece): (i) PE-EVA diffusing film (DF), with pearl-based pigments to highly diffuse radiation, and (ii) PE-LLDPE reflective-diffusive film $(R D F)$, which contains tiny aluminum particles to reflect the NIR solar spectrum. The two films include anti-drip additive, and their optical properties were measured after removing this additive from the film's surface (the supplier's information). The third was PE-LD film, locally produced by Napco Modern Plastic Products Company-Sack Division Ltd., (Dammam, Saudi Arabia). The locally produced film (CF) was used as a control for comparison. The three films included different additives such as UV-stabilizer, antioxidant, plasticizer, etc. However, the exact compositions of these films were kept confidential by the suppliers. The available information about these films is summarized in Table 1.

Table 1. Properties of the three films tested as they were supplied by the producers.

\begin{tabular}{cccc}
\hline $\begin{array}{c}\text { Properties Supplied by the } \\
\text { Producers }\end{array}$ & $\begin{array}{c}\text { PE-EVA, } \\
\text { Diffusive Film (DF) }\end{array}$ & $\begin{array}{c}\text { PE-LLDEP, Reflective } \\
\text { Diffusive Film, (RDF) }\end{array}$ & $\begin{array}{c}\text { PE-LD, Locally } \\
\text { Produced Film (CF) }\end{array}$ \\
\hline Film thickness $(\mu \mathrm{m})$ & 180 & 200 & 200 \\
Diffusion $(\%)$ & 60 & 40 & - \\
PAR transmittance, $\tau_{P A R}(\%)$ & $87-88$ & $78-80$ & $75-80$ \\
NIR transmittance, $\tau_{N I R}(\%)$ & $<17$ & - & - \\
Working temperature $\left({ }^{\circ} \mathrm{C}\right)$ & - & - & $50-80$ \\
Service life $($ year) & $4-5$ & $4-5$ & $2-3$ \\
Local price $\left(\mathrm{US} \$ / \mathrm{m}^{2}\right)$ & 0.73 & 0.73 & 0.41 \\
\hline
\end{tabular}

Most of the suppliers did not provide accurate and sufficient technical information about their products; however, such information is essential for the designers and decision-makers to select a film for specific applications. Therefore, radiometric characterization for these films was performed. The spectral transmittance $\left(\tau_{\lambda}\right)$ and reflectance $\left(\rho_{\lambda}\right)$ of each film were measured at normal incidence using a Black-Comet (Stellar Net Inc., Tampa, FL, USA) spectrophotometer, scanning between 200 
and $2700 \mathrm{~nm}$ at $0.5 \mathrm{~nm}$ intervals in the UV-VIS-IR range and illustrated in Figure 2a,b, respectively. For each film tested, the measured data were averaged over each $5 \mathrm{~nm}$ interval and integrated over 200-2700 $\mathrm{nm}$ to obtain the total transmittance $\left(\tau_{\mathrm{g}}\right)$ and reflectance $\left(\rho_{\mathrm{g}}\right)$ of films to global solar radiation. In addition, the spectral transmittance (Figure 2a) was integrated over 400-700 nm to obtain the film transmittance to the photosynthetically active radiation, PAR $\left(\tau_{P A R}\right)$ and over $700-2700 \mathrm{~nm}$ to obtain the film transmittance to near infra-red radiation, NIR $\left(\tau_{N I R}\right)$. The results of these integrations are illustrated in Table 2. The three films were used to cover three identical small-scale, twin-span, crop-free greenhouse models (Figure 3) to conduct the experiment for evaluation.
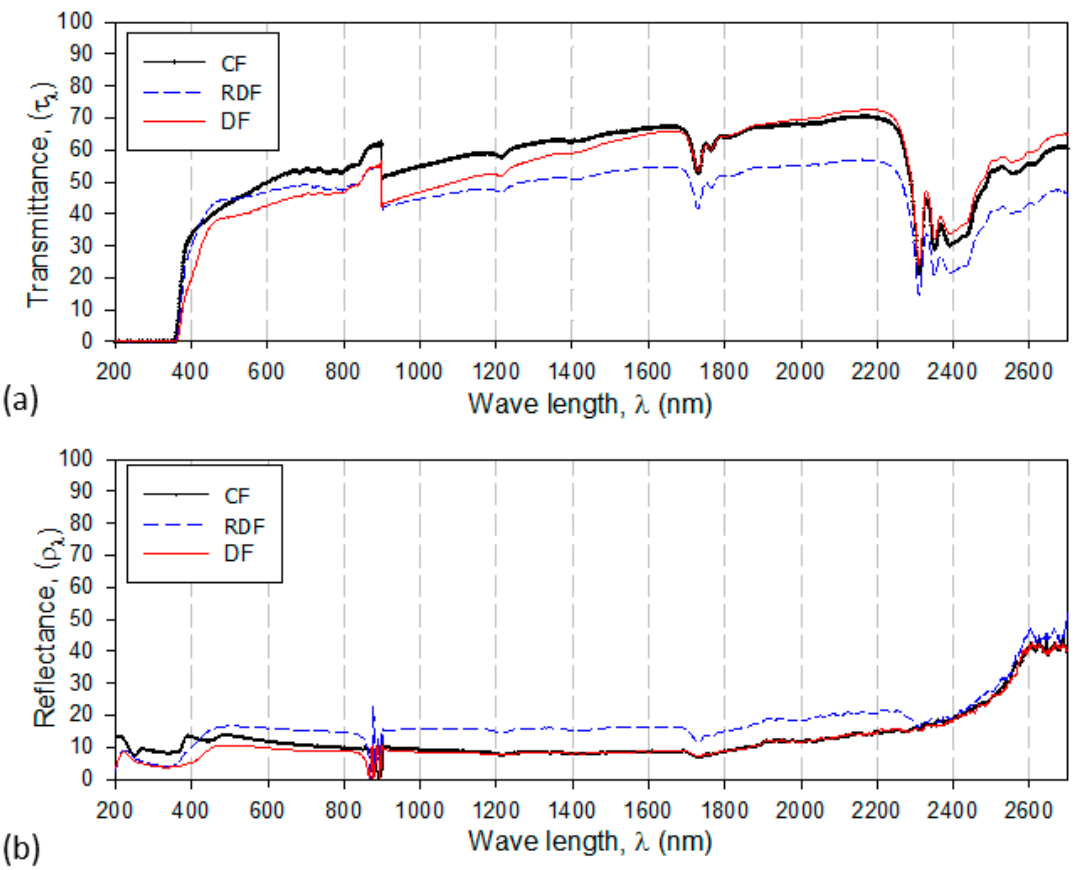

Figure 2. The spectral transmittance (a) and reflectance (b) measured at normal incidence for the three films used for the study.

Table 2. Summary of the main characteristics estimated for the three films tested.

\begin{tabular}{ccccccccc}
\hline Film Cover & $\tau_{P A R}(\mathbf{\%})$ & $\tau_{\text {NIR }}(\mathbf{\%})$ & $\tau_{g}(\mathbf{\%})$ & $\rho_{g}(\mathbf{\%})$ & $\tau_{D}(\%)$ & $\bar{\tau}_{D}(\%)$ & $\sigma(\%)$ & $E(\%)$ \\
\hline$D F$ & 39.8 & 57.4 & 51.0 & 12.5 & 76.0 & 133 & 34 & 77 \\
$R D F$ & 45.0 & 47.8 & 44.2 & 18.5 & 65.0 & 122 & 33 & 85 \\
$C F$ & 46.2 & 59.0 & 53.5 & 13.5 & 77.0 & 162 & 43 & 109 \\
\hline
\end{tabular}

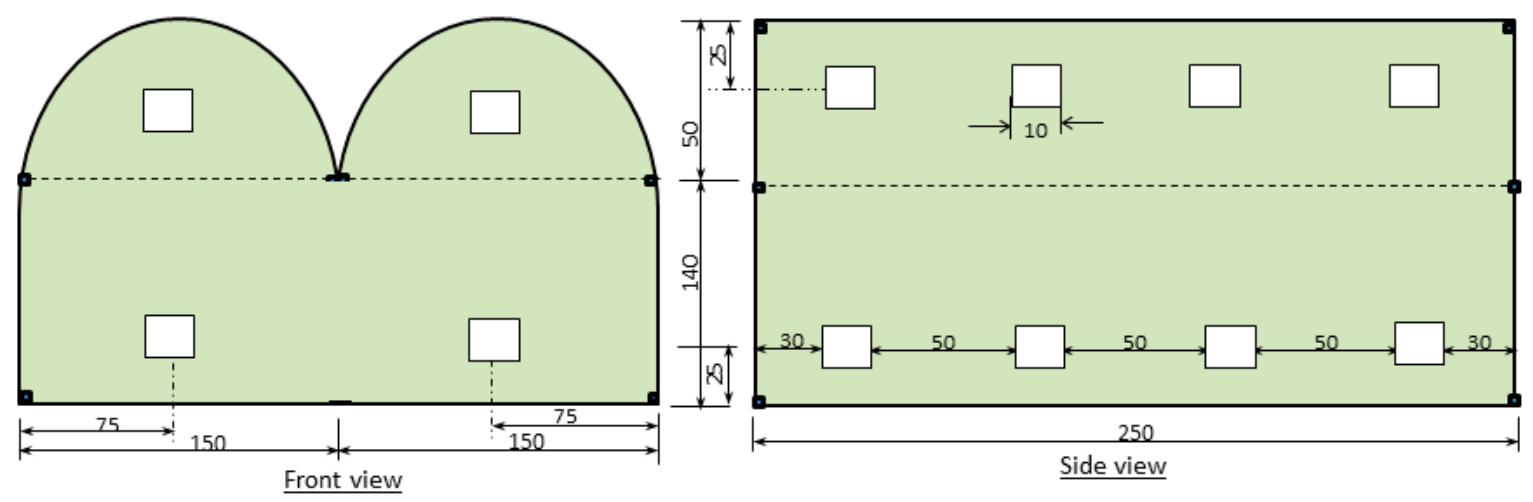

Figure 3. Schematic diagram showing the naturally ventilated twin-span greenhouse model, covered with a plastic film, used for the study; dimensions are in $\mathrm{cm}$, not to scale. 


\subsection{Experimental Procedures and Measurements}

Three experiments were conducted at the Agricultural Research and Experiment Station, Agriculture Engineering Department, King Saud University (Riyadh, Saudi Arabia, $46^{\circ} 47^{\prime}$ E, longitude and $24^{\circ} 39^{\prime} \mathrm{N}$, latitude). The first experiment was conducted to the three twin-spans greenhouse models, covered with the $D F, R D F$, and $C F$ (one for each model) from 28 September to 3 October 2019. The second experiment was conducted during 6-7 October 2019 to examine the effect of tilting the shaded pyranometer on a horizontal plane on the pyranometer measurements. The third experiment was conducted from 14-17 October 2019 to determine the correction factors for the shaded pyranometers used inside and outside the three models. Details of the three experiments are in the following section.

\subsubsection{Experiment in the Three Greenhouse Models}

Three identical twin-spans greenhouse models were used; the outline dimensions of the models are illustrated, not to scale, in Figure 3. The three models were covered simultaneously with the diffusive film $(D F)$, the reflective-diffusive film $(R D F)$, and the locally produced film $(C F)$. The three models were naturally ventilated using square holes $(10 \times 10 \mathrm{~cm})$ made in the cover films; the models were oriented in the $\mathrm{N}-\mathrm{S}$ direction (Figure 3). The air temperatures and relative humidity inside and outside each greenhouse model $\left(T_{\mathrm{i}}, R H_{\mathrm{i}}, T_{\mathrm{o}}\right.$, and $\left.R H_{\mathrm{o}}\right)$ were measured with DMA033 thermo-hygrometers (LSI Lastem, Milano, Italy). Eight CMP3 pyranometers (Kipp \& Zonen B.V. Inc., Bohemia, NY, USA) were used, "each having a time response of $18 \mathrm{~s}$, a maximum error of $\pm 2 \%$, a sensitivity of $5-20 \mu \mathrm{V} / \mathrm{W} \mathrm{m}{ }^{-2}$, a working temperature range of -40 to $+80^{\circ} \mathrm{C}$, and a wavelength range of 310-2800 nm". Four of them were shaded with black-painted wooden disks, $32 \mathrm{~cm}$ in diameter, (shaded pyranometers), to be installed inside and outside the greenhouse models (one for each model) for measuring the diffuse radiation outside $\left(D_{\mathrm{i}}\right)$ and inside $\left(D_{\text {tot }}\right)$ each model. To conscientiously shade the pyranometer sensors in the shaded pyranometers, the pyranometer-disks configuration (as the pyranometer number (1) in Figure 4) was manually oriented toward the sun disk and adjusted every $20 \mathrm{~min}$ to make the incidence angle of solar beam very close to zero. The remaining four pyranometers were kept unshaded for measuring the global radiation inside and outside the greenhouse models $\left(S_{\mathrm{i}}\right.$ and $\left.S_{\mathrm{t}}\right)$. The measurements were made every minute, averaged over $15 \mathrm{~min}$ intervals, and recorded in a data logger (LI-1400, 9 channels, LI-COR, Inc., Lincoln, Nebraska, USA). The measuring devices had been calibrated before use by the supplier.

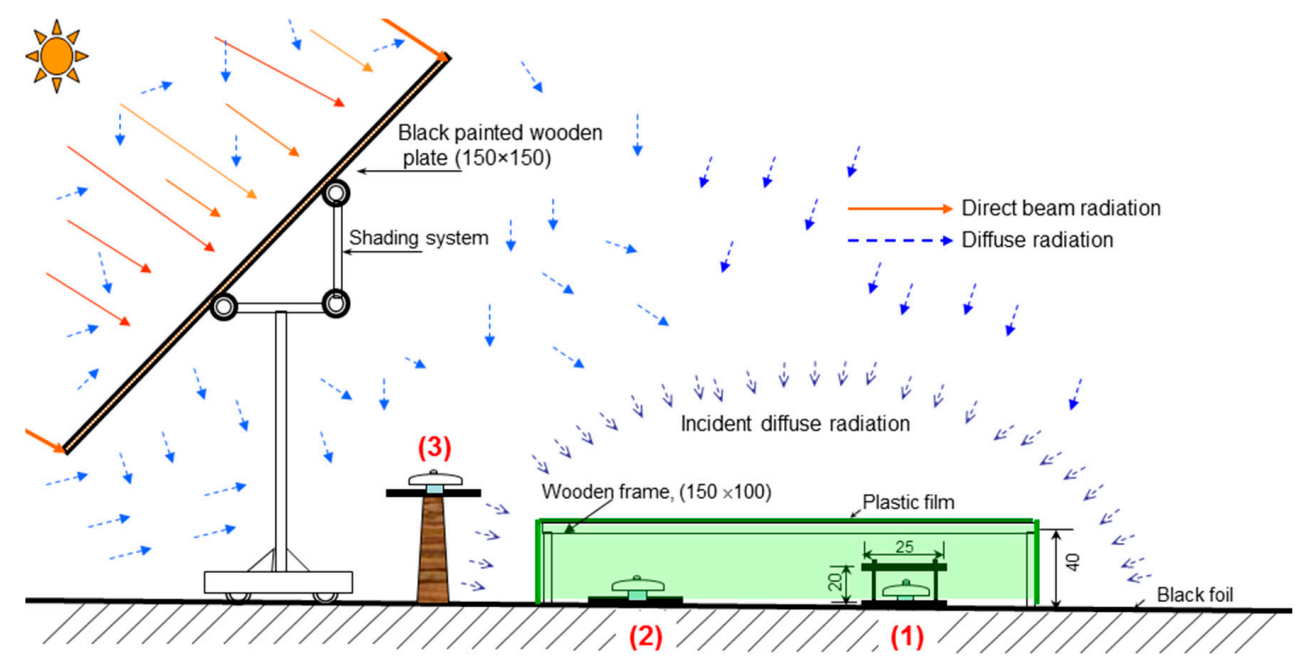

Figure 4. Experimental setup and the shading system used to estimate the correction factors of the shaded pyranometers, and the true transmittance of the film to diffuse solar radiation. Dimensions are in $\mathrm{cm}$, not to scale, and (1), (2) and (3) are the pyranometer numbers. 


\subsubsection{Experiment to Examine the Effect of Tilting on the Shaded Pyranometer Readings}

During the daytime, the global incident solar radiation flux $\left(S_{\mathrm{i}}\right)$ is usually measured by a pyranometer fixed in a horizontal plane. Tilting the pyranometer will affect the measured value of $S_{\mathrm{i}}$ according to the tilting angle on the horizontal plane. On the other hand, the shaded pyranometer used to detect the incident and transmitted diffuse radiation $\left(D_{\mathrm{i}}\right.$ and $\left.D_{\text {tot }}\right)$ was tilted according to the sun elevation to keep the pyranometer dome always shaded during measurements. Since the diffuse radiation incidents and transmits diffusively and the pyranometer receives diffuse radiation from the whole directions, previous studies assumed that the effect of the pyranometer tilting on the measured values of $D_{\mathrm{i}}$ and $D_{\text {tot }}$ is insignificant and can be neglected [22,23]. To emphasize this assumption, an experiment was conducted to measure $D_{\mathrm{i}}$ using three pyranometers, fixed on three positions (horizontally tilted at 45 and $90^{\circ}$ on the horizontal plane). During two days of measurements, the measured values of $D_{\mathrm{i}}$ by the three pyranometers were almost similar (data are not shown); the average absolute difference (max-min) between $D_{\mathrm{i}}$ of the three positions was $3.2 \mathrm{Wm}^{-2}$. This assures the accuracy of the assumption that tilting a pyranometer measuring diffuse radiation up to $90^{\circ}$ on the horizontal plane does not jeopardize the accuracy of measurements.

\subsubsection{Experiment for Determining the Correction Factors of the Shaded Pyranometers}

The upper disk of the shaded pyranometer prevents a portion of diffuse radiation from reaching the pyranometer. Therefore, a correction factor $\left(F_{c}\right)$ is used to compensate the diffuse radiation that was prevented by the upper disk. Four correction factors were required for the study. One was to correct the measured value of the incident diffuse solar radiation $\left(D_{\mathrm{i}}\right)$ outside the greenhouse models $\left(F_{\mathrm{c}-\mathrm{o}}\right)$. Additionally, three $\left(F_{\mathrm{c}-\mathrm{DF}}, F_{\mathrm{c}-\mathrm{RDF}}\right.$, and $\left.F_{\mathrm{c}-\mathrm{CF}}\right)$ were to correct the transmitted diffuse radiation measured inside the greenhouse models $\left(D_{\text {tot }}\right)$ covered with the $D F, R D F$, and $C F$ films, respectively.

An experiment was conducted (Figure 4 ) to determine the values of $F_{\mathrm{c}-\mathrm{o}}, F_{\mathrm{c}-\mathrm{DF}}, F_{\mathrm{c}-\mathrm{RDF}}$, and $F_{\mathrm{c}-\mathrm{CF}}$. Shaded and unshaded pyranometers (number (1) and (2) in Figure 4) were fixed on the floor that was covered with a black cloth to eliminate the upward diffuse reflection. A black-painted wooden frame $(150 \times 100 \times 50 \mathrm{~cm})$ was covered with the three films $(D F, R D F$, and $C F)$ for three consecutive days, one day for each film covering, and placed over the two pyranometers (Figure 4). In addition, an unshaded pyranometer was fixed on a wooden pillar beside the frame to measure the incident diffuse radiation $\left(D_{\mathrm{i}}\right)$ over each film covering the wooden frame. In order to make the configuration, shown in Figure 4 , receive diffuse solar radiation from all directions, a shading system was installed a few meters away from the frame. A detailed description of the shading system is reported in [22]. The experiment was conducted on clear sunny days (14-17 October 2019). The measurements of the three pyranometers in Figure 4 were recorded in the data-logger at 5 min intervals.

For each film tacked on the frame (Figure 4), values of $D_{\text {tot }}$ under a film were measured by using pyranometers (1) and (2), $\left(D_{\text {tot-1 }}\right.$ and $\left.D_{\text {tot-2 }}\right)$; then, the correction factor $\left(F_{\mathrm{c}}\right)$ for each film was estimated as $D_{\text {tot- } 2} / D_{\text {tot- } 1}$. The time course of the measured ratios $D_{\text {tot- } 2} / D_{\text {tot- } 1}$ (i.e., $F_{\mathrm{c}-\mathrm{DF}}, F_{\mathrm{c}-\mathrm{RDF}}$ and $\left.F_{\mathrm{c}-\mathrm{CF}}\right)$ is plotted in Figure 5. To determine the correction factor for the shaded pyranometer outside the greenhouse model, the experiment was repeated on another day with the absence of films and frames, and the time course of the measured ratio of $D_{\text {tot- } 2} / D_{\text {tot- } 1}\left(F_{\mathrm{c}-\mathrm{o}}\right)$ is plotted in Figure 5 . A mean value of 1.95 for the $F_{\mathrm{c}-\mathrm{o}}$ was determined for the shaded pyranometer measuring $D_{\mathrm{i}}$ outside the greenhouse model, and mean values of 2.05, 2.17, and 2.31 for $F_{\mathrm{c}-\mathrm{DF}}, F_{\mathrm{c}-\mathrm{RDF}}$, and $F_{\mathrm{c}-\mathrm{CF}}$ were determined for the shaded pyranometers measuring $D_{\text {tot }}$ under the $D F, R D F$, and $C F$, respectively. 


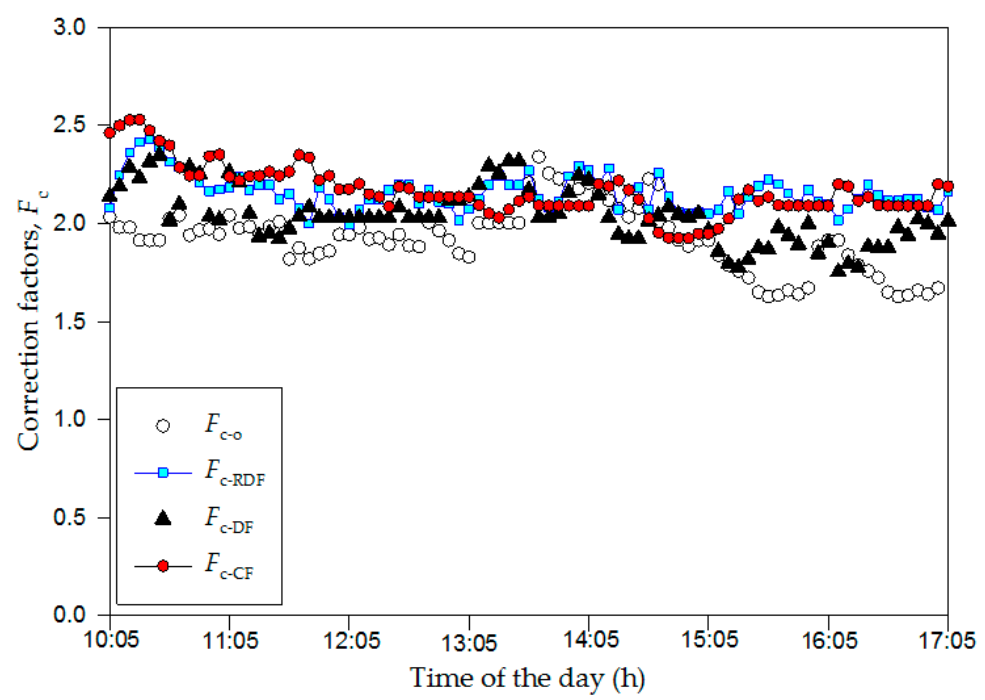

Figure 5. Time course of the correction factors estimated for the shaded pyranometers under the three films tested, and outside the greenhouse models; all were under diffuse radiation conditions (14-17 October 2019).

In parallel to the correction factors, the value of the true transmittance to diffuse radiation $\left(\tau_{D}\right)$ was measured for each film to be used in Equations (4) and (5). Therefore, for each film tacked on the frame (Figure 4$), \tau_{D}$ is the ratio between $D_{t}$ and $D_{i}\left(D_{\mathrm{t}} / D_{\mathrm{i}}\right)$ measured by using pyranometers (2) and (3), respectively (Figure 4). The time course of the true transmittances $\left(\tau_{D}\right)$ measured for the three films is depicted in Figure 6. Mean values of $\tau_{D}$ as $0.77,0.76$, and 0.65 were determined for the $C F, D F$, and $R D F$ covers, respectively.

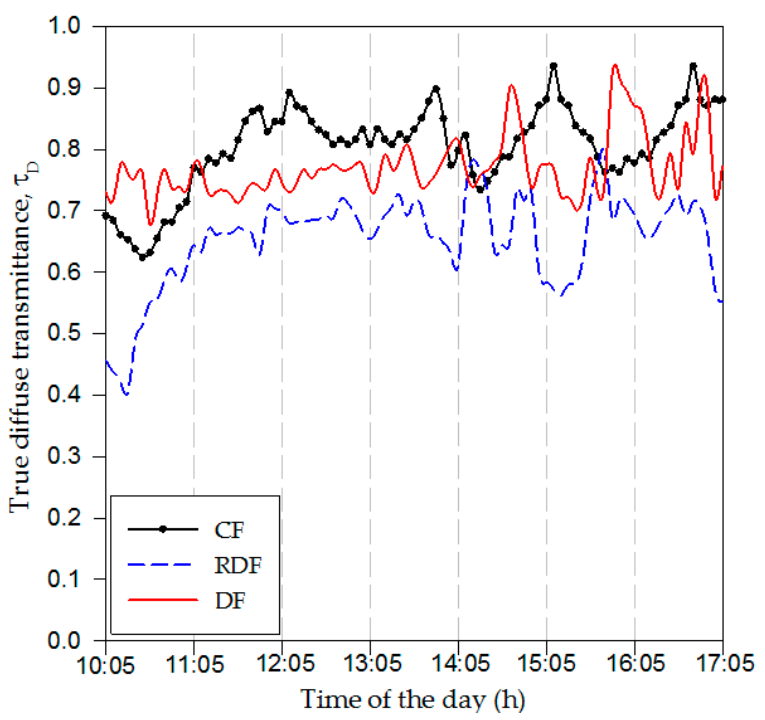

Figure 6. Time course of the true transmittances of the three films to diffuse radiation $\left(\tau_{D}\right)$; the films and the pyranometers were exposed to diffuse radiation, (14-16 October 2019).

\section{Results and Discussion}

\subsection{Diffusion Characteristics of the Tested Films}

One of the main advantages of using diffusive plastic films for covering greenhouses is their ability to diffuse a portion of beam radiation during transmission. Enhancing diffuse radiation would allow plants in the greenhouse to receive solar radiation from all sides for stimulating photosynthesis and better growth. The transmitted diffuse radiation fluxes $\left(D_{\text {tot }}\right)$ in the three greenhouse models covered 
with the $D F, R D F$, and $C F$ and that incident outside the greenhouse $\left(D_{\mathrm{i}}\right)$ are illustrated in Figure $7 \mathrm{a}$, and the unscattered beams incident $\left(B_{\mathrm{i}}\right)$ and transmitted $\left(B_{\mathrm{u}}\right)$ are illustrated in Figure $7 \mathrm{~b}$. Figure $7 \mathrm{a}$ shows that the three films increased the diffuse radiation inside the greenhouses much higher than the outside $\left(D_{\text {tot }}>D_{\mathrm{i}}\right)$. The locally produced film (CF) shows the highest diffusive power, followed by the diffusive film $(D F)$, then the reflective-diffusive film $(R D F)$. For simplicity, the daily integral for the diffuse radiation fluxes $\left(D_{\text {tot }}\right.$ and $D_{\mathrm{i}}$ in Figure $\left.7 \mathrm{a}\right)$ and the unscattered beams radiation fluxes $\left(\mathrm{B}_{\mathrm{u}}\right.$ and $B_{\mathrm{i}}$ in Figure $7 \mathrm{~b}$ ) were determined. The outside incident $D_{\mathrm{i}}$ and $B_{\mathrm{i}}$ were 5.0 and $17.0 \mathrm{MJ} \mathrm{m}^{-2}$, whereas the inside $D_{\text {tot }}$ and $B_{\mathrm{u}}$ were 7.0 and $9.0 \mathrm{MJ} \mathrm{m}^{-2}$ under the $D F$ cover; 6.0 and $8.6 \mathrm{MJ} \mathrm{m}^{-2}$ under the $R D F$ cover; 8.3 and $8.7 \mathrm{MJ} \mathrm{m}^{-2}$ under the $C F$ cover. Accordingly, the diffusive nature of the tested covers increased the ratio of diffuse to direct beam radiation $(D / B)$ from 0.3 outside the greenhouse to 0.77 , 0.69 , and 0.95 inside a greenhouse covered with $D F, R D F$, and $C F$, respectively.

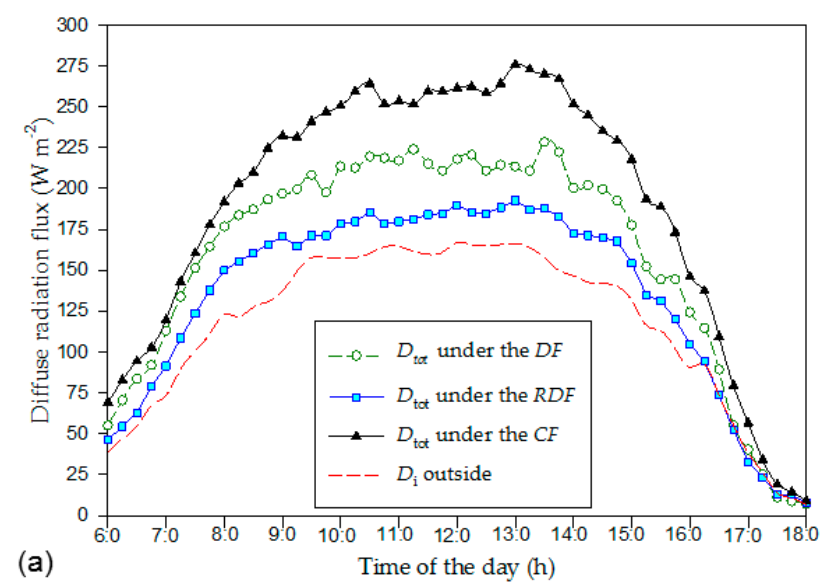

(a)

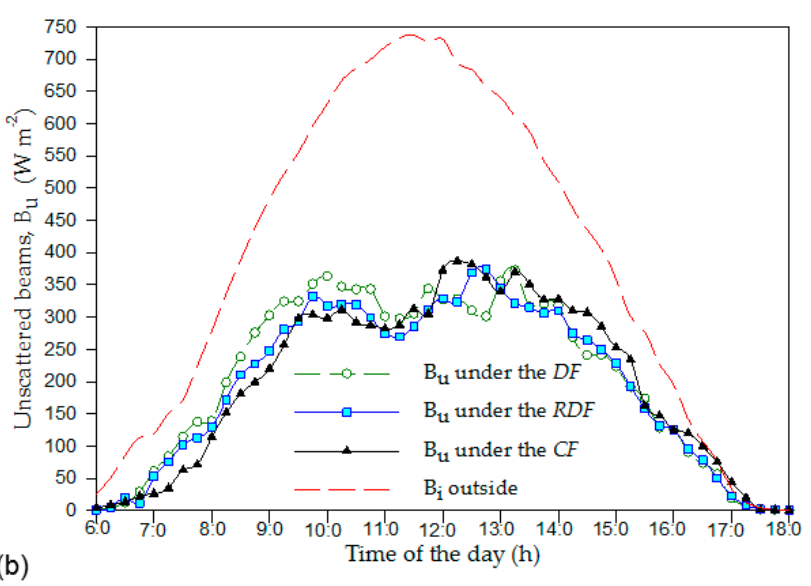

Figure 7. Diurnal variations of (a) the incident $\left(D_{\mathrm{i}}\right)$ and transmitted $\left(D_{\text {tot }}\right)$ diffuse radiation fluxes into the three greenhouse models, and $(\mathbf{b})$ the unscattered beams radiation incident $\left(B_{i}\right)$ and transmitted $\left(B_{\mathrm{u}}\right)$ into the three greenhouse models on a sunny day (30 September 2019).

The two properties that describe the power of a film cover to diffuse solar beams radiation during transmission are the true and apparent transmittances $\left(\tau_{D}\right.$ and $\left.\bar{\tau}_{D}\right)$. The time course of $\tau_{D}$ is illustrated in Figure 6 to describe the transmittances of the three films to the incident diffuse radiation (i.e., $D_{\mathrm{t}} / D_{\mathrm{i}}$ in Figure 1$)$, and by definition, the $\tau_{D}$ value is usually less than one. However, the apparent transmittances $\left(\bar{\tau}_{D}\right)$ of the three film covers (i.e., $D_{\text {tot }} / D_{\mathrm{i}}$ in Figure 1 ) are higher than one (Figure 8), because each cover film has converted a portion of solar beams to diffuse radiation during transmission. In Figure 8, the $C F$ cover shows the highest capability to diffuse beams radiation followed by the $D F$ and $R D F$ covers. The value of $\bar{\tau}_{D}$ depends on the type of additives that were included to produce the film. Even though the $R D F$ film cover was characterized by the producer as a reflective film, it also showed a diffusion 
property (Figure 8). In addition, the locally produced CF film serves mainly to resist the harsh weather conditions in arid regions; this cover showed a higher diffusive power than the $D F$ and RDF covers (Figure 8). Based on the data in Figure 8, the daily averages of the apparent transmittance $\left(\bar{\tau}_{D}\right)$ were $1.62,1.33$, and 1.22 for the $C F, D F$, and $R D F$ covers, respectively, compared to the true transmittance $\left(\tau_{D}\right)$ values of $0.77,0.76$, and 0.65 in Figure 6.

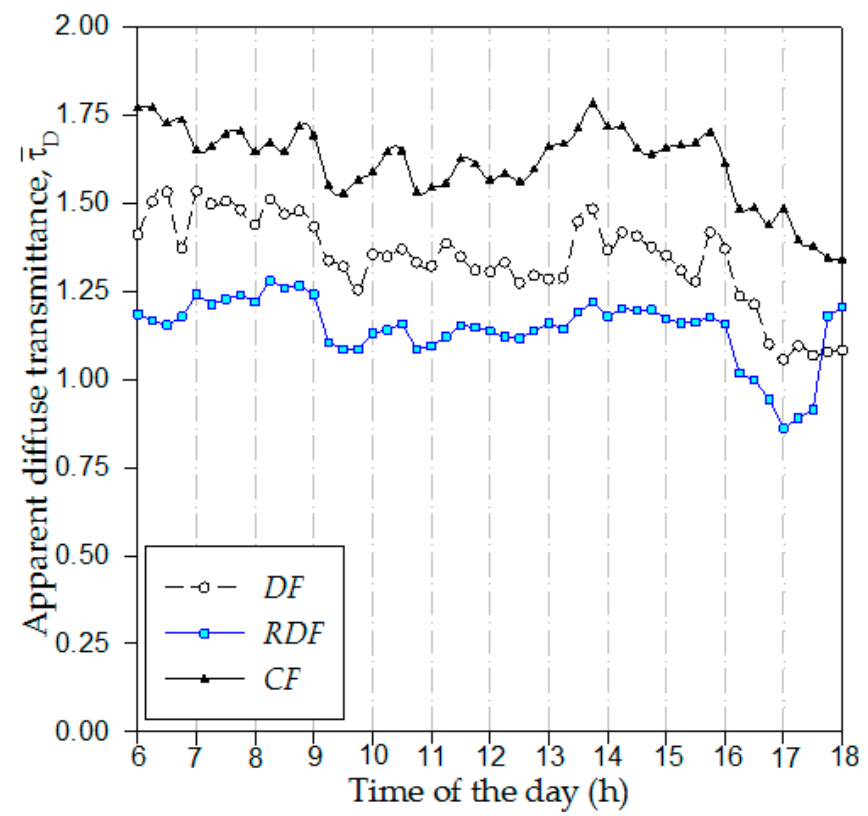

Figure 8. The diurnal variations of the apparent transmittances $\left(\bar{\tau}_{D}\right)$ were estimated for the three films covered greenhouses (the diffusive, $D F$, reflective-diffusive, $R D F$, and control, $C F$ ) on a sunny day (30 September 2019).

The scattering or diffusion coefficient (fraction of the transmitted beam radiation that was diffused during transmission $\sigma$ ) was estimated for the three film covers by using Equation (4), and the diurnal variation of $\sigma$ is illustrated in Figure 9. The value of $\sigma$ depended on the microscopic structure of the cover film combined with the incidence angle of solar beam radiation. Scattering or diffuse reflection of beams radiation follows, in most cases, the reflection's law; therefore, the value of $\sigma$ increased with increase of the incident angle of the solar beam. In the early morning and late afternoon, most of the transmitted beams were diffused (Figure 9), and the value of $\sigma$ is expected to reach one at sunrise and sunset times. The mean values of $\sigma$ were estimated as $0.34,0.33$, and 0.44 for the $D F, R D F$, and $C F$ covers, respectively. The three tested films enhanced the transmitted diffuse radiation. The percentage of diffuse radiation gained under the three film covers $(E)$ was estimated using Equation (5) on a sunny day (30 September 2019) and the mean values of $E$ were $77 \%, 85 \%$, and $109 \%$ for the $D F, R D F$, and $C F$, respectively. These results indicate that the reflective-diffusive film $(R D F)$ has a similar capability to diffuse beam radiation as the diffusive film $(D F)$; however, the locally produced film $(C F)$ diffused beam radiation much more than the $D F$ and $R D F$ films. For an overall evaluation, the main properties characterizing the three film covers are summarized in Table 2. The value of $E(\%)$ depends on $\tau_{D}$ and $\bar{\tau}_{D}$; therefore, as shown in Table 2, the RDF cover enhanced the transmitted diffuse radiation more than the $D F$ cover, even though the $\tau_{D}$ of the $D R F$ was lower than that of the $D F$ (Table 2). 


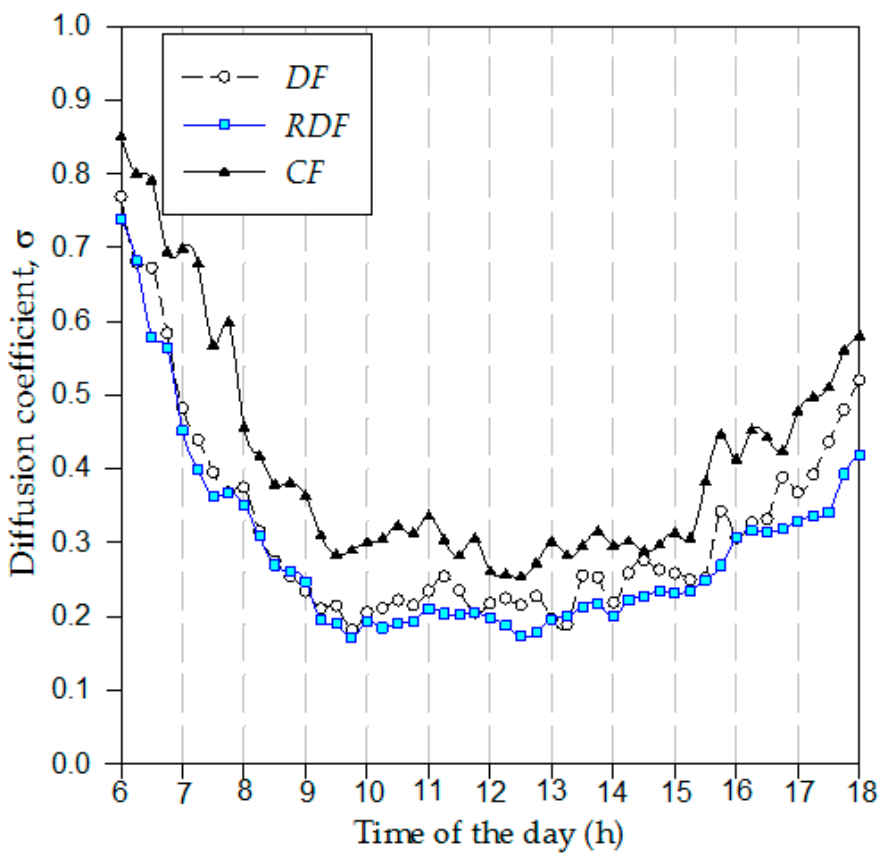

Figure 9. Diurnal variation of the diffusion coefficient $(\sigma)$ estimated for the three films covered greenhouses on a sunny day (30 September 2019).

\subsection{The Microclimate under the Three Covers}

Due to the greenhouse effect, the inside air temperature increases drastically during the daytime, much more than the outside air temperature. This, in turn, makes the relative humidity in the greenhouse lower than the outside. Figures 10 and 11 illustrate the diurnal variation (for three consecutive days) of air temperature and relative humidity inside $\left(T_{\mathrm{i}}\right.$ and $\left.R H_{\mathrm{i}}\right)$ and outside $\left(T_{\mathrm{o}}\right.$ and $R H_{\mathrm{o}}$ ) the three greenhouse models, covered with the $D F, R D F$, and $C F$. The air temperature inside the three greenhouse models $\left(T_{\mathrm{i}}\right)$ on the first day (30 September 2019) was relatively lower than the other two days because the ventilation rate was higher on the first day (the front and back sides of each model cover were opened). Figure 10 shows that at around noon, the air temperature under the $C F$ cover $\left(T_{\mathrm{i}}, C F\right)$ was about $5-10^{\circ} \mathrm{C}$ lower than that under the $D F$ and $R D F$ covers $\left(T_{\mathrm{i}}, D F\right.$, and $\left.T_{\mathrm{i}}, R D F\right)$. These results are in accordance with results reported in previous studies that used NIR-reflecting film covers for reducing the inside greenhouse air temperature. For example in the summer months of southern Spain, the NIR-reflecting plastic film covering reduced the inside greenhouse air temperature by $4.5^{\circ} \mathrm{C}$ at noon [24]; another study in the same climate reported that a PE film cover with NIR-reflecting pigment reduced the greenhouse air by $3{ }^{\circ} \mathrm{C}$ at around noon, compared to the standard PE cover without additives [25]. NIR-reflecting film covering a greenhouse model reduced the inside air temperature by $2{ }^{\circ} \mathrm{C}$ at noon compared to a model covered with a standard film [26]. In the current study, the values of $T_{\mathrm{i}}$ under the $D F$ and $R D F$ covers were almost the same during the last two days. This is because the reflectance of the RDF ( $\rho_{\mathrm{g}}$ in Table 2$)$ is only $5 \%-6 \%$ higher than the other films. Therefore, the $R D F$ cover did not reduce $T_{\mathrm{i}}$ compared to the $D F$ cover because the $R D F$ cover reflectance was low. On the other hand, the $R H_{\mathrm{i}}$ increases with a decrease in $T_{\mathrm{i}}$; thus, $R H_{\mathrm{i}}$ under the $C F$ cover is relatively higher (3\%-5\%) than $R H_{\mathrm{i}}$ under the $D F$ and $R D F$ covers during the daytime (Figure 11). Moreover, the $D F$ and $R D F$ covers did not improve (via increasing) the $R H_{\mathrm{i}}$ (Figure 11), and the three films showed nearly the same effect in $R H_{\mathrm{i}}$ during nighttime. 


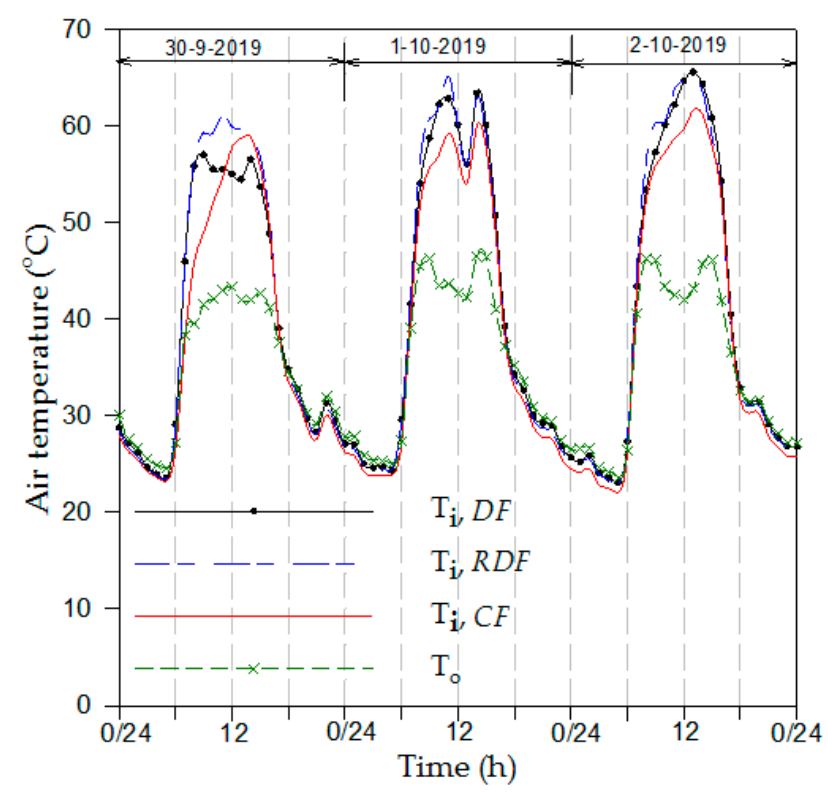

Figure 10. Time courses of the air temperature inside the greenhouse models covered with the $D F$, $R D F$, and CF films and outside the models.

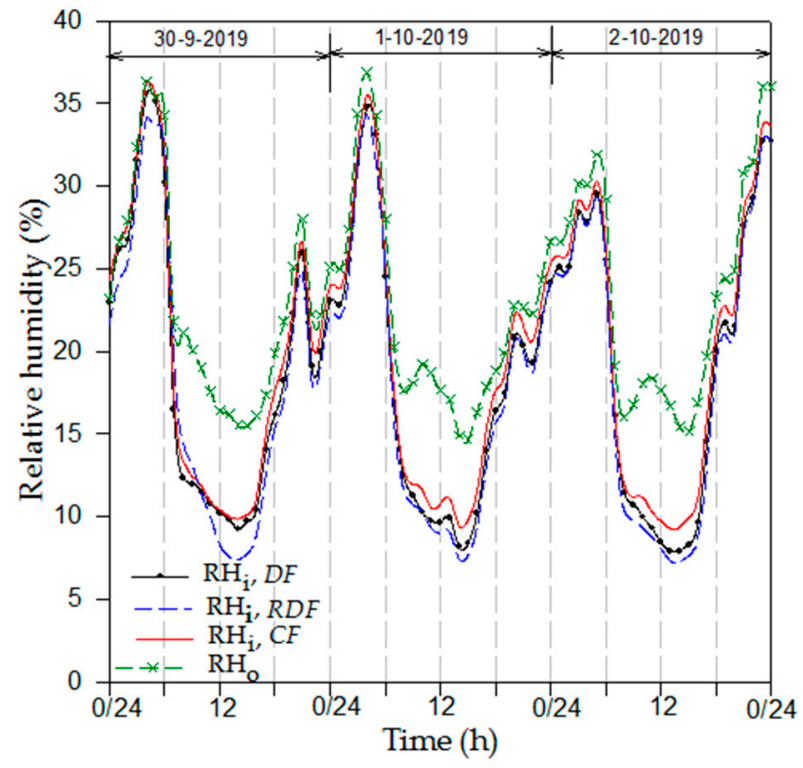

Figure 11. Time courses of the air relative humidity inside the greenhouse models covered with the $D F$, $R D F$, and $C F$ films and outside the models.

In greenhouses, in general, more than $70 \%$ of the transmitted solar radiation, $S_{t}$, (measured in Watt per unit area of floor surface) is transformed to sensible heat used to increase the greenhouse air temperature [27]. In the small-scale experimental greenhouse models (as the one used in the current study) the inside air volume to floor surface area ratio is low. Therefore, the $T_{\mathrm{i}}$ increase is high, as affected by the high solar radiation transmission per unit volume of air; consequently, the effect of the cover type in reducing the $T_{\mathrm{i}}$ and increasing $R H_{\mathrm{i}}$ is insignificant. On the other hand, these effects are expected to be more significant with increases in the air volume to floor surface area ratio for large-scale and commercial greenhouses.

Comparing the $C F$ cover with the $D F$ and $D R F$ covers, we found that (i) the $C F$ cover is cheaper, however, its service life is shorter (Table 1), therefore, determining its financial impact is quite difficult; (ii) the $C F$ cover shows a higher diffusion capability and a higher PAR transmissivity (Table 2), which are extremely important for crop growth; and (iii) even though the $C F$ cover shows a higher global 
and NIR solar radiation transmission, the environment under this cover was the best (in terms of air temperature decreases and relative humidity increases). The better environment under the $C F$ cover may be attributed to the high diffusion of the beams' radiation during transmission through this cover. High solar beam diffusion may enhance the uniformity of the environmental parameters under the cover and increase the radiation loss from the greenhouse envelope and consequently, moderate the microclimate under the $C F$ cover.

\section{Conclusions and Recommendation}

This study characterized the transmission of solar radiation through three types of plastic films that are commonly used for covering greenhouses in the Arabian Peninsula. These films were diffusive film $(D F)$, reflective-diffusive film $(R D F)$, and locally produced film $(C F)$ as a control treatment. The characterization was based on a simplified theoretical analysis aided by measuring global and diffuse solar radiation, simultaneously, inside and outside greenhouse models that were covered with these films. Based on the presented results, the main conclusions may be summarized as follows:

- The three films tested (i.e., $C F, D F$, and $R D F$ ) were able to diffuse the solar beams radiation transmitted through them; they diffused $43 \%, 34 \%$, and $33 \%$ of the transmitted beam radiation, respectively, during transmission. The three covers increased the diffuse to direct beam radiation ratio from 0.3 outside the greenhouse models to $0.95,0.77$, and 0.69 under the $C F, D F$, and $R D F$ covers, respectively.

- Even though the reflectance of the RDF cover is 5\%-6\% higher than the $C F$ and $D F$ covers, it shows a similar effect on the inside greenhouse air temperature as the $D F$ cover; however, the $C F$ cover decreased the inside air temperature by about $5-10{ }^{\circ} \mathrm{C}$ (at around noon) and increased the relative humidity by $4 \%-5 \%$ compared to those under the $D F$, and $D R F$ covers.

- During nighttime, the three film covers show nearly the same effects on the air temperature and relative humidity inside the greenhouse models.

- The $C F$ cover shows a better performance in terms of diffusion and improving the microclimate inside the greenhouse model and this improvement is expected to increase with the increase in the greenhouse volume (i.e., large-scale and commercial greenhouses); this film cover can be used effectively in arid climates.

- It is quite difficult to conclude the financial impact of using the $C F$ cover because its low price is allocated with the relatively low service life of the film (Table 1).

Among the three covers tested, the CF had the highest global and NIR transmittance, low reflectance, and the highest diffusive capability (Table 2). These properties allocated with the best environment under this cover (i.e., the decrease in air temperature and increase in relative humidity). Accordingly, diffusion may offer a cooling effect on the greenhouse air temperature; this issue needs to be addressed properly to explore the effect of diffuse radiation, instead of direct beam radiation, in reducing the inside greenhouse air temperature and increasing relative humidity.

Author Contributions: Conceptualization, A.A.-G. and I.A.-H.; methodology, A.A.-G.; validation, A.A. and A.I.; formal analysis, I.A.-H.; investigation, A.A.-G.; resources, M.S.; data creation, M.S., A.I.; writing-original draft preparation, I.A.-H.; writing—review and editing, A.A.-G.; visualization, M.S.; supervision, I.A.-H.; project administration, A.A. All authors have read and agreed to the published version of the manuscript.

Funding: This research received no external funding.

Acknowledgments: The authors would like to extend their sincere appreciation to the deanship of scientific research at King Saud University for funding this research through research group number RG 1435-074.

Conflicts of Interest: The authors declare no conflict of interest. 


\section{Nomenclature}

$B_{\mathrm{i}} \quad$ direct beam solar radiation incident on the cover film $\left(\mathrm{W} \mathrm{m}^{-2}\right)$

$B_{\mathrm{t}} \quad$ direct beam radiation transmitted through the cover film $\left(\mathrm{W} \mathrm{m}^{-2}\right)$

$B_{\mathrm{u}} \quad$ unscattered beam radiation transmitted into the greenhouse $\left(\mathrm{W} \mathrm{m}^{-2}\right)$

CF locally produced film was used as control

$D / B \quad$ ratio of diffuse to direct beam radiation inside or outside the greenhouse

DF diffusive film cover

$D_{\mathrm{i}} \quad$ atmospheric diffuse radiation incident on the greenhouse cover $\left(\mathrm{W} \mathrm{m}^{-2}\right)$

$D_{\mathrm{t}} \quad$ atmospheric diffuse radiation transmitted through the cover $\left(\mathrm{W} \mathrm{m}^{-2}\right)$

$D_{\text {tot }} \quad$ total diffuse radiation flux measured inside the greenhouse $\left(\mathrm{W} \mathrm{m}^{-2}\right)$

$D_{\text {tot-1 }} \quad$ total diffuse radiation flux measured by pyranometer (1) under a film $\left(\mathrm{W} \mathrm{m}^{-2}\right)$

$D_{\text {tot-2 }} \quad$ total diffuse radiation flux measured by pyranometer (2) under a film $\left(\mathrm{W} \mathrm{m}^{-2}\right)$

E

$F_{\mathrm{c}} \quad$ correction factor of a shaded pyranometer (-)

$F_{\mathrm{c}-\mathrm{o}} \quad$ correction factor of a shaded pyranometer outside the greenhouse (-)

$F_{\mathrm{c}-\mathrm{CF}} \quad$ correction factor of a shaded pyranometer under the $C F$ cover (-)

$F_{\mathrm{c}-\mathrm{DF}} \quad$ correction factor of a shaded pyranometer under the $D F$ cover (-)

$F_{\mathrm{c}-\mathrm{RDF}} \quad$ correction factor of a shaded pyranometer under the $R D F$ cover (-)

PAR the photosynthetically active radiation $(400-700 \mathrm{~nm})\left(\mathrm{W} \mathrm{m}^{-2}\right)$

$R D F \quad$ reflective-diffusive film cover

$R H_{\mathrm{i}} \quad$ relative humidity of the air inside the greenhouse model

$\mathrm{RH}_{\mathrm{O}} \quad$ relative humidity of the air outside the greenhouse model

$S_{\mathrm{i}} \quad$ global solar radiation flux incident on the greenhouse cover $\left(\mathrm{W} \mathrm{m}^{-2}\right)$

$S_{t} \quad$ global solar radiation flux transmitted through the cover film $\left(\mathrm{W} \mathrm{m}^{-2}\right)$

$T_{\mathrm{i}} \quad$ air temperature inside the greenhouse model $\left({ }^{\circ} \mathrm{C}\right)$

$T_{\mathrm{O}} \quad$ air temperature outside the greenhouse model $\left({ }^{\circ} \mathrm{C}\right)$

$\rho_{g}$ total reflectance of the cover film to global solar radiation (\%)

$\sigma \quad$ diffusion coefficient (-)

$\tau_{D} \quad$ true transmittance of the cover film to diffuse radiation

$\bar{\tau}_{D}$

\section{References}

1. Ghani, S.; El-Bialy, E.M.A.A.; Bakochristou, F.; Rashwan, M.M.; Abdelhalim, A.M.; Ismail, S.M.; Ben, P. Experimental and numerical investigation of the thermal performance of evaporative cooled greenhouses in hot and arid climates. Sci. Technol. Built Environ. 2019, 1-20. [CrossRef]

2. Hesham, A.A.; Tong, Y.X.; Yang, Q.C.; Al-Faraj, A.A.; Abdel-Ghany, A.M. Spatial distribution of air temperature and relative humidity in the greenhouse as affected by external shading in arid climates. J. Integr. Agric. 2019, 18, 2869-2882.

3. Al-Helal, I.A. Effects of ventilation rate on the environment of a fan-pad evaporatively cooled, shaded greenhouse in extreme arid climates. Appl. Eng. Agric. 2007, 23, 221-230. [CrossRef]

4. Semar, A.; Hartani, T.; Bachir, H. Soil and water salinity evaluation in new agriculture land under arid climate, the case of the Hassi Miloud area, Algeria. Euro-Mediterr. J. Environ. Integr. 2019, 4, 40. [CrossRef]

5. Abdel-Ghany, A.M.; Al-Helal, I.M.; El-zahrani, S.M.; Alsadon, A.A.; Ali, I.M.; Elleithy, R.M. Covering materials incorporating radiation-preventing techniques to meet greenhouse cooling challenges in arid regions: A review. Sci. World J. TSWJ 2012. [CrossRef]

6. Sethi, V.P.; Sharma, S.K. Survey of cooling technologies for worldwide agricultural greenhouse applications. Sol. Energy 2007, 81, 447-1459. [CrossRef]

7. Syed, K.H.G.; Abdel-Ghany, A.M.; Al-Helal, I.M.; El-zahrani, S.M.; Alsadon, A.A. Evaluation of PE film having NIR-reflective additives for greenhouse applications. Adv. Mater. Sci. Eng. 2013, 2013, 575081. [CrossRef] 
8. Verlodt, I.; Verschaeren, P. New interference film for climate control. Acta Hortic. 2000, 514, $139-146$. [CrossRef]

9. Hemming, S.; Swinkels, G.L.A.M.; van Breugel, A.J.; Mohammadkhani, V. Evaluation of diffusing properties of greenhouse covering materials. Acta Hortic. 2016, 1134, 309-316. [CrossRef]

10. Hemming, S.; Mohammadkhani, V.; van Ruijven, J. Material technology of diffuse greenhouse covering materials-Influence on light transmission, light scattering and light spectrum. Acta Hortic. 2014, 1037, 883-895. [CrossRef]

11. Dueck, T.; Janse, J.; Li, T.; Kempkes, F.; Eveleens, B. Influence of diffuse glass on the growth and production of tomato. Acta Hortic. 2012, 956, 75-82. [CrossRef]

12. Markvart, J.; Rosenqvist, E.; Aaslyng, J.M.; Ottosen, C.O. How is canopy photosynthesis and growth of chrysanthemums affected by diffuse and direct light? Eur. J. Hortic. Sci. 2010, 75, 253-258.

13. Tavares, C.; Goncalves, A.; Castro, P.; Loureiro, D.; Joyce, A. Modeling an agriculture production greenhouse. Renew. Energy 2001, 22, 15-20. [CrossRef]

14. Papadakis, G.; Manolakos, D.; Kyritsis, S. Solar radiation transmissivity of a single-span greenhouse through measurements on scale models. J. Agric. Eng. Res. 1998, 71, 331-338. [CrossRef]

15. Balocco, C.; Mercatelli, L.; Azzali, N.; Meucci, M.; Grazzini, G. Experimental transmittance of polyethylene films in the solar and infrared wavelengths. Sol. Energy 2018, 165, 199-205. [CrossRef]

16. Graefe, J.; Sandmann, M. Shortwave radiation transfer through a plant canopy covered by single and double layers of plastic. Agric. Forest Meteorol. 2015, 201, 196-208. [CrossRef]

17. Aldaftari, H.A.; Okajima, J.; Komiya, A.; Maruyama, S. Radiative control through greenhouse covering materials using pigmented coatings. J. Quant. Spectrosc. Radiat. Trans. 2019, 231, 29-36. [CrossRef]

18. Mobtaker, H.G.; Ajabshirchi, Y.; Ranjbar, S.F. Simulation of thermal performance of solar greenhouse in north-west of Iran: An experimental validation. Renew. Energy 2019, 135, 88-97. [CrossRef]

19. Emekli, N.Y.; Buyuktas, K.; Bascetincelik, A. Changes of light transmittance of the LDPE films during the service life for greenhouse application. J. Build. Eng. 2016, 6, 126-132. [CrossRef]

20. Xie, X.; Liu, Y.-J.; Hao, J.-J.; Ju, L.; Du, W.-C.; Yang, H.-W. Feasibility study of a new solar greenhouse covering material. J. Quant. Spectrosc. Radiat. Trans. 2019, 224, 37-43. [CrossRef]

21. Pollet, I.V.; Pieters, J.G.; Deltour, J.; Verschoore, R. Diffusion of radiation transmitted through dry and condensate covered transmitting materials. Sol. Energy Mater. Sol. Cells 2005, 86, 177-196. [CrossRef]

22. Abdel-Ghany, A.M.; Al-Helal, I.M. Characterization of solar radiation transmission through plastic shading nets. Sol. Energy Mater. Sol. Cells 2010, 94, 1371-1378. [CrossRef]

23. Burek, S.A.M.; Norton, B.; Probert, S.D. Transmission and forward scattering of insolation through plastic (transparent and semi-transparent) materials. Sol. Energy 1989, 42, 457-475. [CrossRef]

24. Garcia-Alonso, Y.; Espi, E.; Salmeron, A.; Fontecha, A.; Gonzalez, A.; Lopez-Marin, J. New cool plastic films for greenhouse covering in tropical and subtropical areas. Acta Hortic. 2006, 719, 131-137. [CrossRef]

25. Lopez-Marin, J.; Gonzalez, A.; Garcia-Alonso, Y.; Espi, E.; Salmeron, A.; Fontecha, A.; Real, A.I. Use of cool plastic films for greenhouse covering in Southern Spain. Acta Hortic. 2008, 801, 181-186. [CrossRef]

26. Hemming, S.; Kempkes, F.; van der Braak, N.; Dueck, T.; Marissen, N. Greenhouse cooling by NIR-reflection. Acta Hortic. 2006, 719, 97-105. [CrossRef]

27. Abdel-Ghany, A.M. Solar energy conversions in the greenhouses. Sustain. Cities Soc. 2011, 1, $219-226$. [CrossRef]

(C) 2020 by the authors. Licensee MDPI, Basel, Switzerland. This article is an open access article distributed under the terms and conditions of the Creative Commons Attribution (CC BY) license (http://creativecommons.org/licenses/by/4.0/). 